\title{
Influence of anxiety on health outcomes in COPD
}

\author{
Mark D Eisner, ${ }^{1,2}$ Paul D Blanc, ${ }^{1,2}$ Edward H Yelin, ${ }^{3}$ Patricia P Katz, ${ }^{3}$ Gabriela Sanchez, ${ }^{4}$ \\ Carlos Iribarren, ${ }^{4}$ Theodore A Omachi ${ }^{1}$
}

${ }^{1}$ Division of Pulmonary and Critical Care Medicine, Department of Medicine University of California, San Francisco, USA

${ }^{2}$ Division of Occupational and Environmental Medicine, Department of Medicine, University of California, San Francisco, USA ${ }^{3}$ Institute for Health Policy Studies, Department of Medicine, University of California, San Francisco, USA ${ }^{4}$ Division of Research, Kaiser Permanente, Oakland, California, USA

\section{Correspondence to}

Dr Mark D Eisner, University of California, San Francisco, 505 Parnassus Avenue, M1097, San Francisco, CA 94143-0111, USA; mark.eisner@ucsf.edu

Received 26 August 2009 Accepted 11 December 2009

\begin{abstract}
Background Psychological functioning is an important determinant of health outcomes in chronic lung disease. To better define the role of anxiety in chronic obstructive pulmonary disease (COPD), a study was conducted of the inter-relations between anxiety and COPD in a large cohort of subjects with COPD and a matched control group.
\end{abstract}

Methods Data were used from the FLOW (Function, Living, Outcomes, and Work) cohort of patients with COPD ( $n=1202)$ and matched controls without COPD $(n=302)$. Anxiety was measured using the Anxiety subscale of the Hospital Anxiety and Depression Scale.

Results COPD was associated with a greater risk of anxiety in multivariable analysis (OR 1.85; 95\% Cl 1.072 to 3.18 ). Among patients with COPD, anxiety was related to poorer health outcomes including worse submaximal exercise performance (less distance walked during the 6min walk test: -66.3 feet for anxious vs non-anxious groups; $95 \% \mathrm{Cl}-127.3$ to -5.36 ) and a greater risk of self-reported functional limitations (OR 2.41; 95\% Cl 1.71 to 3.41). Subjects with COPD with anxiety had a higher longitudinal risk of COPD exacerbation in Cox proportional hazards analysis after controlling for covariates (HR 1.39; 95\% Cl 1.007 to 1.90 ).

Conclusion COPD is associated with a higher risk of anxiety. Once anxiety develops among patients with COPD, it is related to poorer health outcomes. Further research is needed to determine whether systematic screening and treatment of anxiety in COPD will improve health outcomes and prevent functional decline and disability.

Chronic obstructive pulmonary disease (COPD) is an important cause of respiratory symptoms, disability and other poor health outcomes. Recent clinical trials have advanced the treatment of COPD by establishing a beneficial effect of inhaled medications on longer term health outcomes. ${ }^{1-4}$ Nonetheless, many patients continue to suffer from marked respiratory symptoms and activity limitation despite optimal medical management.

A conundrum of COPD treatment is that patients with a given level of lung function may differ substantively in their symptom burden and activity limitation. Other factors beyond the respiratory system must exert important impacts on clinical outcomes. ${ }^{5}$ Psychological functioning in particular may influence why two patients with the same degree of lung function impairment have different health outcomes. ${ }^{6}$

Anxiety is likely to be a problem for many patients with COPD. The symptom of dyspnoea, which is a cardinal manifestation of COPD, can be a potent stimulus for anxiety. ${ }^{7}$ Inability to perform daily activities or fulfil expected social roles may also lead to anxiety. Cigarette smoking, which is the primary cause of COPD, has also been strongly linked to anxiety symptoms. ${ }^{8}$ Furthermore, some COPD treatments such as $\beta$ agonists and theophylline-containing medications may increase symptoms of anxiety and panic.

There remain significant unanswered questions about the prevalence and impact of anxiety among patients with COPD. Although the prevalence of anxiety is probably high in COPD, most studies have not included an adequate control group to estimate the RR. ${ }^{9}$ A recent workshop conducted by the American College of Chest Physicians concluded that further research was needed to assess the impact of anxiety on health outcomes. ${ }^{9}$ In particular, the influence of COPD severity on the risk of anxiety has not been adequately characterised. Moreover, the impact of anxiety on the risk of COPD exacerbations is not clear. ${ }^{10}$

To evaluate these issues, we studied the interrelations between anxiety and COPD in a large cohort of subjects with COPD and a matched control group. We theorised that COPD increases the risk of anxiety and that, among patients with established disease, greater disease severity increases the likelihood of anxiety which, in turn, leads to poorer health outcomes. The FLOW (Function, Living, Outcomes, and Work) study, which was designed to evaluate the development of disability in COPD, prespecified this analysis of anxiety and COPD.

\section{METHODS}

The FLOW study of COPD is an ongoing prospective cohort study of adult members of an integrated healthcare delivery system with a physician's diagnosis of COPD and an accompanying matched control group. Recruitment methods have been previously reported in detail (see online supplement). ${ }^{5} 61112$ We recruited a cohort of 1202 members of the Kaiser Permanente Medical Care Program who had recently been treated for COPD using a validated algorithm based both on healthcare utilisation and pharmacy dispensing for COPD. ${ }^{13}$ A control group of 302 subjects without COPD matched by age, sex and race to the cohort members were also recruited. At baseline assessment, structured telephone interviews that ascertained sociodemographic characteristics, COPD clinical history and health status were conducted. ${ }^{511} 12$ Research clinic visits included spirometry and other physical assessments.

\section{Measurement of anxiety}

We used a concept of anxiety based on the Diagnostic and Statistical Manual of Mental Disorders (DSM-IV) as a state characterised by cognitive 
features (fearful thoughts, difficulty concentrating), emotional response (apprehension, nervousness), behavioural symptoms (agitated movements, hand wringing, pacing) and physiological arousal (sweating, palpitations, muscle tension). ${ }^{14}$ Anxiety was measured using the 7-item anxiety subscale of the Hospital Anxiety and Depression Scale, which is a widely used validated instrument designed to detect clinically significant anxiety among patients who attend outpatient medical clinics. ${ }^{15} 16$ The anxiety scale score ranges from 0 to 21 , with higher scores reflecting more severe anxiety. We used the recommended optimal cutting point of $8 / 9$ points to identify subjects with significant anxiety. ${ }^{17}$ In secondary analysis we also used the suggested score ranges to define moderate (11-14 points) and severe anxiety (15-21 points). The scale has been previously used to measure anxiety in COPD. ${ }^{1018} 19$ We have previously reported our findings for depression in COPD. ${ }^{6}$

\section{Assessment of COPD severity}

A combined approach was used to measure COPD severity. We used a disease-specific COPD severity score that we had previously developed and validated for use in epidemiological and outcomes research. ${ }^{20}$ Based on survey responses, the COPD severity score comprises five overall aspects of COPD severity: respiratory symptoms; systemic corticosteroid use; other COPD medication use; previous hospitalisation or intubation for respiratory disease; and home oxygen use. Each item was weighted based on clinical aspects of the disease and its expected contribution to overall COPD severity. Possible total scores range from 0 to 35 , with higher scores reflecting more severe COPD.

We also used the validated BODE index, which is a multimodal measure of disease severity. ${ }^{21}$ The BODE index is based on the body mass index (B), the degree of airflow obstruction $(\mathrm{O})$ measured by forced expiratory volume in $1 \mathrm{~s}\left(\mathrm{FEV}_{1}\right)$, grade of dyspnoea (D) assessed by the modified Medical Research Council (MRC) dyspnoea scale ${ }^{22}$ and exercise capacity (E) measured by the 6-min walk test. Each component is assigned a specific index and the total score ranges from 0 to 10 points (higher scores indicate greater severity). The BODE index predicts death and other poor outcomes in COPD. ${ }^{21} 2324$ We have reported elsewhere that the BODE and COPD severity instruments provide independent explanatory power in relation to disease status. ${ }^{25}$ Because we posited that dyspnoea may be an important cause of anxiety, the MRC dyspnoea scale score was also evaluated as a separate measure.

\section{Pulmonary function impairment}

To assess respiratory impairment, spirometric measurements were conducted according to American Thoracic Society (ATS) guidelines. $^{26}{ }^{27}$ We used the EasyOne Frontline spirometer (ndd Medical Technologies, Chelmsford, Massachusetts, USA), which is known for its reliability, accuracy and durability. ${ }^{28} 29$ The Easyone spirometer has been used by large-scale multicentre international epidemiological studies of COPD. ${ }^{29} 30$ Because research clinic examinations were conducted by trained nonmedical personnel, we did not administer bronchodilators for study purposes. However, $90 \%$ of subjects had taken their own short-acting bronchodilator within $4 \mathrm{~h}$ of spirometry or had taken a long-acting bronchodilator earlier in the same day.

\section{Patient-centred health outcomes}

At the time of the telephone interview, generic physical health status was measured with the Short Form (SF)-12 Physical Component Summary (PCS) score. The SF-12 is derived from the Medical Outcomes Study SF-36 instrument, which is the most widely used measure of generic health status. Defined from the eight SF-36 subscales by factor analysis, the PCS score reflects an underlying physical dimension of physical healthrelated quality of life (HROL). ${ }^{31}$ Higher scores reflect more favourable health states. We also used the Airways Questionnaire 20 revised (AQ-20R) to measure disease-specific HROL. ${ }^{32} 33$ This validated instrument has excellent psychometric properties for assessing HROL in persons with airway disease including COPD. Higher scores correspond to poorer HRQL. ${ }^{32} 34$

Submaximal exercise performance was measured using the 6-min walk test which has been widely used in studies of COPD. ${ }^{3536}$ We used a standardised flat straight course of $30 \mathrm{~m}$ in accordance with ATS guidelines. ${ }^{37}$ Subjects who routinely used home oxygen or who had a resting oxygen saturation $<90 \%$ were supplied with supplemental oxygen during the test. Every 2 min the technician used standardised phrases to encourage effort, as recommended by the ATS guidelines. The primary outcome measured was the total distance walked in $6 \mathrm{~min}$.

Self-reported functional limitation was measured using a previously validated approach. ${ }^{38}$ The scale is comprised of 10 questions that assess the degree of difficulty in multiple domains of basic physical functioning such as pushing, stooping, kneeling, getting up from a standing position, lifting lighter or heavier objects, standing, sitting, standing from a seated position, walking up stairs and walking in the neighbourhood. Subjects who indicate "a lot of difficulty" with one or more functions or not doing a function because they were unable or they were told by a doctor not to do so are defined by this measure as having a self-reported functional limitation. ${ }^{38}$

\section{Longitudinal COPD outcomes: COPD exacerbations}

Emergency department (ED) visits and hospitalisation for COPD were used as proxy measures of severe disease exacerbation. ED visits and hospitalisations were ascertained from Kaiser Permanente computerised healthcare databases that capture complete healthcare utilisation at its facilities. These outcomes were measured from the time of completion of the baseline interviews until the time of data acquisition. The median duration of follow-up was 2.1 years (25th-75th IOR $1.7-2.6$ years). During the follow-up period there were 76 hospitalisations and $244 \mathrm{ED}$ visits for COPD.

COPD-related hospitalisation was defined as those with a principal ICD-9 discharge diagnosis code for COPD (491,492, or 496). COPD-related ED visits were identified as those with an ICD-9 code for COPD. A composite outcome for hospital-based care was defined as either an ED visit or hospitalisation for COPD.

\section{Covariates}

We selected covariates that may be related to anxiety. These included sociodemographic characteristics such as age, sex, educational attainment and income, which were measured as previously described. 561112 Cigarette smoking was assessed using questions developed for the National Health Interview Survey. ${ }^{39}$ Because cardiovascular conditions may be associated with anxiety, we assessed comorbid cardiovascular conditions using survey items modified from the National Health Interview Survey. ${ }^{40}$ These include a reported physician's diagnosis of coronary artery disease, congestive heart failure and hypertension.

\section{Statistical analysis}

Statistical analysis was conducted using SAS software Version 9.1 (SAS Institute Inc). Bivariate analysis was conducted with the $t$ test for continuous variables and $\chi^{2}$ test for dichotomous 
variables. Multivariable logistic regression analysis was used to examine the impact of COPD on the risk of anxiety compared with controls without COPD after controlling for potential confounders.

In our theoretical model of anxiety and COPD we posit that greater disease severity increases the risk of anxiety which, in turn, leads to poorer health outcomes. Moreover, anxiety may also feed back to increase disease severity and indirectly affect health outcomes. Logistic regression analysis was used to assess the impact of COPD severity on the risk of anxiety. Multivariable analysis was performed to control for the potential confounding effects of age, sex, race, educational attainment, income and smoking history. Continuous predictor variables were scaled by dividing by one-half SD which corresponds approximately with the minimal clinically important difference. ${ }^{41}$

We then examined the impact of anxiety on patient-centred outcomes using multivariable linear regression for continuous outcome variables (PCS-12 scores, AQ-20R scores and SMWT distance) and logistic regression for binary outcome variables (functional limitations). Cox proportional hazards analysis was used to evaluate the longitudinal relationship between baseline anxiety and the subsequent risk of COPD exacerbation. Schoenfeld residuals were used to evaluate the proportional hazards assumption; no evidence of violation was found. ${ }^{42}$ Kaplan-Meier curves were also generated to display the risk of COPD exacerbation for subjects with COPD with and without anxiety.

To test for an exposure-response relationship between degree of anxiety and the risk of COPD exacerbation, we defined an ordinal variable based on the total anxiety score (no anxiety=0, mild $=1$, moderate $=2$, severe=3). Consequently, the $\mathrm{HR}$ is expressed for a one-category increase in anxiety level.

We evaluated the impact of concurrent depression, as measured by the Geriatric Depression Scale Short-Form, on the results for anxiety. The impact of depression on COPD-related health outcomes in the FLOW cohort has been previously reported in detail. ${ }^{6}$ Substantive depressive symptoms occurred in less than half of the subjects with COPD with anxiety (44\%). To examine the effect of depression we repeated the analysis of anxiety and health outcomes (both patient-centred outcomes and longitudinal risk of COPD exacerbations) with inclusion of an interaction term for anxiety and depression (in the respective linear regression and Cox proportional hazards analysis). ${ }^{43}$ The Wald $\chi^{2}$ test was used to test the statistical significance of interaction terms. There was no statistical evidence for interaction in any case $(p>0.20)$, indicating that depression did not modify the impact of anxiety on health outcomes. Consequently, depression was not further considered in the analysis.

\section{RESULTS}

\section{COPD and the risk of anxiety}

The unadjusted prevalence of anxiety was higher among those with COPD $(15 \%)$ than in controls $(6 \% ; \mathrm{p}<0.0001)$ (table 1$)$. As shown in table 1 , anxiety was associated with several demographic and other personal factors including younger age, female sex, non-white race, lower socioeconomic status and current smoking. The pattern of results was similar for control subjects without COPD, although only age was statistically significant owing to the smaller size of the control group. Figure 1 shows the prevalence of mild, moderate and severe anxiety among those with and without COPD.

COPD was associated with a greater risk of anxiety in both unadjusted (OR 2.64; 95\% CI 1.62 to 4.31) and multivariable analysis (OR 1.85; 95\% CI 1.072 to 3.18 ) (table 2). When $\mathrm{FEV}_{1}$
Table 1 Baseline characteristics and anxiety

\begin{tabular}{|c|c|c|c|c|}
\hline & \multicolumn{2}{|c|}{ COPD $(n=1202)$} & \multicolumn{2}{|c|}{ Controls $(n=302)$} \\
\hline & $\begin{array}{l}\text { No anxiety } \\
(\mathrm{n}=1024)\end{array}$ & $\begin{array}{l}\text { Anxiety } \\
(n=181)\end{array}$ & $\begin{array}{l}\text { No anxiety } \\
(\mathrm{n}=283)\end{array}$ & $\begin{array}{l}\text { Anxiety } \\
(n=19)\end{array}$ \\
\hline Age (mean years, SD) & $59(6)$ & $55(6.6)^{*}$ & $59(6.1)$ & $55(6.6) \dagger$ \\
\hline Female sex (n, \%) & $563(55 \%)$ & $128(71 \%)^{*}$ & $107(38 \%)$ & $10(53 \%)$ \\
\hline Race (white, non-Hispanic) & $698(68 \%)$ & $112(62 \%) \ddagger$ & $94(53 \%)$ & $8(42 \%)$ \\
\hline \multicolumn{5}{|l|}{ Educational attainment $(n, \%)$} \\
\hline High school or less & $288(28 \%)$ & $64(35 \%)^{*}$ & $39(14 \%)$ & $3(16 \%)$ \\
\hline Some college & $436(43 \%)$ & $88(49 \%)$ & $88(31 \%)$ & $7(37 \%)$ \\
\hline College degree or higher & $297(29 \%)$ & $29(16 \%)$ & $156(55 \%)$ & $9(47 \%)$ \\
\hline \multicolumn{5}{|l|}{ Household income $(n, \%)$} \\
\hline Low income & $93(9 \%)$ & $36(20 \%)^{*}$ & $8(3 \%)$ & $1(5 \%)$ \\
\hline Medium income & $595(58 \%)$ & $104(57 \%)$ & $127(45 \%)$ & $10(53 \%)$ \\
\hline High income & $252(25 \%)$ & $24(13 \%)$ & $126(45 \%)$ & $7(37 \%)$ \\
\hline \multicolumn{5}{|l|}{ Smoking history $(\mathrm{n}, \%)$} \\
\hline Past smoker & $565(55 \%)$ & $79(44 \%)^{*}$ & $123(43 \%)$ & $9(47 \%)$ \\
\hline Current smoker & $311(30 \%)$ & $82(45 \%)$ & $11(4 \%)$ & $1(5 \%)$ \\
\hline Never smoker & $145(14 \%)$ & $20(11 \%)$ & 149 (53\%) & $9(47 \%)$ \\
\hline Mean (SD) FEV ${ }_{1}(\mathrm{I})$ & $1.78(0.8)$ & $1.88(0.8) \neq$ & $2.73(0.7)$ & $3.03(0.8) \neq$ \\
\hline Mean (SD) BMI $\left(\mathrm{kg} / \mathrm{m}^{2}\right)$ & $32(8)$ & $32(8)$ & $30(6)$ & $30(8)$ \\
\hline \multicolumn{5}{|l|}{ Cardiovascular comorbidity } \\
\hline Coronary artery disease & $112(11 \%)$ & $27(15 \%)$ & $8(2.8 \%)$ & $0(0 \%)$ \\
\hline Hypertension & $551(54 \%)$ & $106(59 \%)$ & $112(40 \%)$ & $6(32 \%)$ \\
\hline Congestive heart failure & $112(11 \%)$ & $24(13 \%)$ & $0(0 \%)$ & $0(0 \%)$ \\
\hline
\end{tabular}

$\mathrm{p}$ Values for categorical outcomes (educational attainment, household income and smoking history) were for the overall comparison of all categories.

A minority of the cohort (8\%) declined to report their income.

${ }^{*} p<0.001$ for comparison of subjects with anxiety vs no anxiety.

$\dagger p<0.05$ for comparison of subjects with anxiety vs no anxiety.

$\neq \mathrm{p}<0.10$

$\mathrm{BMI}$, body mass index; COPD, chronic obstructive pulmonary disease; $\mathrm{FEV}_{1}$, forced expiratory volume in $1 \mathrm{~s}$.

was additionally added to the multivariable model to account for lung function differences among subjects with COPD and controls, COPD remained related to a higher risk of anxiety (OR 2.23; 95\% CI 1.26 to 3.96) (data not shown).

\section{COPD severity and risk of anxiety}

Higher COPD severity, as measured by the COPD severity score and $\mathrm{BODE}$ index, was associated with a greater risk of anxiety among persons with COPD (table 3). A higher degree of

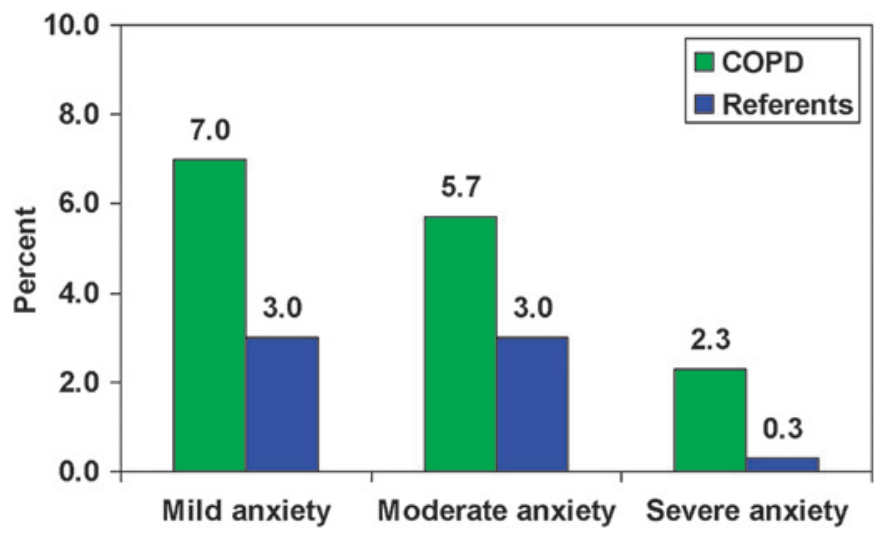

Figure 1 Prevalence of mild, moderate and severe anxiety in patients with chronic obstructive pulmonary disease (COPD) and controls (referents). The overall prevalence of anxiety is $15 \%$ and $6 \%$, respectively, among those with COPD and referents. The bars show the proportion of anxious patients in the mild (8-10 points), moderate (11-14 points), and severe (15-21 points) categories in subjects with COPD (green bars) and referents (blue bars). In each category the likelihood of anxiety was higher in the COPD group $(p=0.0001)$. 
Table 2 Chronic obstructive pulmonary disease (COPD) and the risk of anxiety

\begin{tabular}{|c|c|c|}
\hline \multirow{2}{*}{$\begin{array}{l}\text { Disease } \\
\text { status }\end{array}$} & Unadjusted & Multivariable adjusted* \\
\hline & $\overline{\text { OR }(95 \% \mathrm{Cl})}$ & $\overline{\text { OR }(95 \% \mathrm{CI})}$ \\
\hline Controls & 1.0 (referent) & 1.0 (referent) \\
\hline \multirow[t]{2}{*}{ COPD } & 2.64 (1.62 to 4.31 ) & 1.85 (1.072 to 3.18$)$ \\
\hline & $\mathrm{p}<0.0001$ & $\mathrm{p}=0.027$ \\
\hline
\end{tabular}

Results are from logistic regression analysis and are presented as ORs (95\% Cls)

*Controlling for age, sex, race, educational attainment, household income, and smoking history.

dyspnoea was also related to a greater risk of anxiety. Lung function impairment was not clearly related to anxiety $(p=0.13)$.

\section{Impact of anxiety on patient-centred health outcomes in COPD} Anxiety was associated with poorer patient-centred outcomes including physical health status and disease-specific HROL (table 4). It was also related to poorer distance walked during the 6 -min walk test ( -66.3 feet for anxious vs non-anxious groups; $95 \%$ CI -127.3 to -5.36$)$ and a greater risk of self-reported functional limitations (OR 2.41; 95\% CI 1.71 to 3.41 ).

\section{Anxiety and the prospective risk of COPD exacerbation}

Kaplan-Meier analysis indicated that subjects with COPD with baseline anxiety had a greater risk of COPD exacerbation than those without anxiety (log-rank test, $\mathrm{p}=0.017$, figure 2 ). Subjects with COPD with baseline anxiety had a higher longitudinal risk of COPD exacerbation in Cox proportional hazards analysis after controlling for covariates (HR 1.39; 95\% CI 1.007 to 1.90) (table 5).

There was evidence of an exposure-response relationship between severity of anxiety and the risk of COPD exacerbation. For each increment of anxiety category (ie, mild vs none, moderate vs mild, severe vs moderate) the risk of COPD exacerbation increased (HR 1.27; 95\% CI 1.09 to 1.49). The overall $p$ value for exposure-response trend was 0.0025 .

\section{Anxiety and COPD-related outcomes: COPD severity as a potential mediator}

To examine whether the impact of anxiety on COPD-related health outcomes was mediated by COPD severity, we repeated the multivariable analyses after adding the COPD severity score and BODE index as disease-specific severity measures (table 6). The impact of anxiety on distance walked in 6 min and the risk of COPD exacerbations appeared to be mediated completely by

Table 3 Disease severity and risk of anxiety among 1202 subjects with COPD

\begin{tabular}{|c|c|c|}
\hline \multirow{3}{*}{$\begin{array}{l}\text { COPD severity } \\
\text { measure }\end{array}$} & \multicolumn{2}{|l|}{ Risk of anxiety } \\
\hline & Unadjusted & $\begin{array}{l}\text { Multivariable } \\
\text { adjusted }\end{array}$ \\
\hline & OR (95\% Cl) & OR (95\% CI) \\
\hline \multirow[t]{2}{*}{ COPD severity score } & 1.21 (1.12 to 1.30$)$ & 1.20 (1.11 to 1.31$)$ \\
\hline & $\mathrm{p}<0.0001$ & $\mathrm{p}<0.0001$ \\
\hline \multirow[t]{2}{*}{ BODE index } & 1.17 (1.09 to 1.27$)$ & 1.16 (1.06 to 1.27$)$ \\
\hline & $\mathrm{p}<0.001$ & $\mathrm{p}=0.0008$ \\
\hline \multirow[t]{2}{*}{ MRC dyspnoea score } & $1.38(1.26$ to 1.50$)$ & 1.32 (1.20 to 1.45$)$ \\
\hline & $\mathrm{p}<0.0001$ & $\mathrm{p}<0.0001$ \\
\hline \multirow[t]{2}{*}{$\mathrm{FEV}_{1}$} & $1.07(0.99$ to 1.16$)$ & 1.08 (0.98 to 1.19$)$ \\
\hline & $\mathrm{p}=0.09$ & $p=0.13$ \\
\hline
\end{tabular}

Results are from logistic regression analysis of each severity indicator and the risk of anxiety. Results are expressed as OR per $0.5 \mathrm{SD}$ increment of each severity indicator $(95 \% \mathrm{Cl})$.

Multivariable analysis adjusts for age, sex, race, educational attainment, household income and smoking history.

COPD, chronic obstructive pulmonary disease; $\mathrm{FEV}_{1}$, forced expiratory volume in $1 \mathrm{~s}$.
Table 4 Impact of anxiety on patient-centred outcomes in COPD

\begin{tabular}{lll}
\hline & \multicolumn{2}{l}{$\begin{array}{l}\text { Change in each outcome for anxious vs non- } \\
\text { anxious* }\end{array}$} \\
\cline { 2 - 3 } Outcome measure & Unadjusted & $\begin{array}{l}\text { Multivariable } \\
\text { adjusted }\end{array}$ \\
\hline $\begin{array}{l}\text { Physical health status } \\
\text { (points) }\end{array}$ & -6.24 & -4.66 \\
& $(-8.03$ to -4.44$)$ & $(-6.44$ to -2.89$)$ \\
Disease-specific HROL & $\mathrm{p}<0.0001$ & $\mathrm{p}<0.0001$ \\
(points) & 4.23 & 3.31 \\
& $(3.56$ to 4.95$)$ & $(2.62$ to 4.00$)$ \\
Distance walked in & $\mathrm{p}<0.0001$ & $\mathrm{p}<0.0001$ \\
6 min (feet) & -94.6 & -66.3 \\
& $(-157.7$ to -31.5$)$ & $(-127.3$ to -5.36$)$ \\
Risk of self-reported & $\mathrm{p}=0.0033$ & $\mathrm{p}=0.033$ \\
physical functional & $0 R 2.93$ & $0 R 2.41$ \\
limitations $\dagger$ & $(2.12$ to 4.05$)$ & $(1.71$ to 3.41$)$ \\
\hline
\end{tabular}

Physical health status was measured using the SF-12 Physical Component Summary Score (higher scores reflect better status).

Disease-specific HROL was measured with the Airways Questionnaire 20-R (higher scores reflect poorer status)

Distance walked in 6 min (feet) was measured using the 6-min walk test.

Self-reported functional limitations were assessed using a battery of basic physical activities (see Methods section).

All multivariable analyses controlled for age, sex, race, educational attainment, household income and smoking history.

*Physical health status, disease-specific HROL and distance walked in 6 min were analysed using linear regression analysis; results are expressed as mean change in each outcome measure in the group with anxiety vs referent group.

†Self-reported functional limitations were analysed with logistic regression analysis; results are expressed as $\mathrm{OR}$ for the anxious group vs non-anxious group.

COPD, chronic obstructive pulmonary disease; HROL, health-related quality of life.

COPD severity in that the effect estimates decreased markedly and became statistically non-significant. The association between anxiety and physical health status, disease-specific quality of life and risk of self-reported physical limitations was partly, but not completely, mediated by COPD severity (ie, effect estimates were reduced but not eliminated).

\section{DISCUSSION}

\section{Study findings and integration with previous literature}

COPD was associated with a higher risk of anxiety than a matched control group without the condition. Among a large cohort of patients with COPD, disease severity-as measured by the COPD severity score and BODE index-increased the risk of

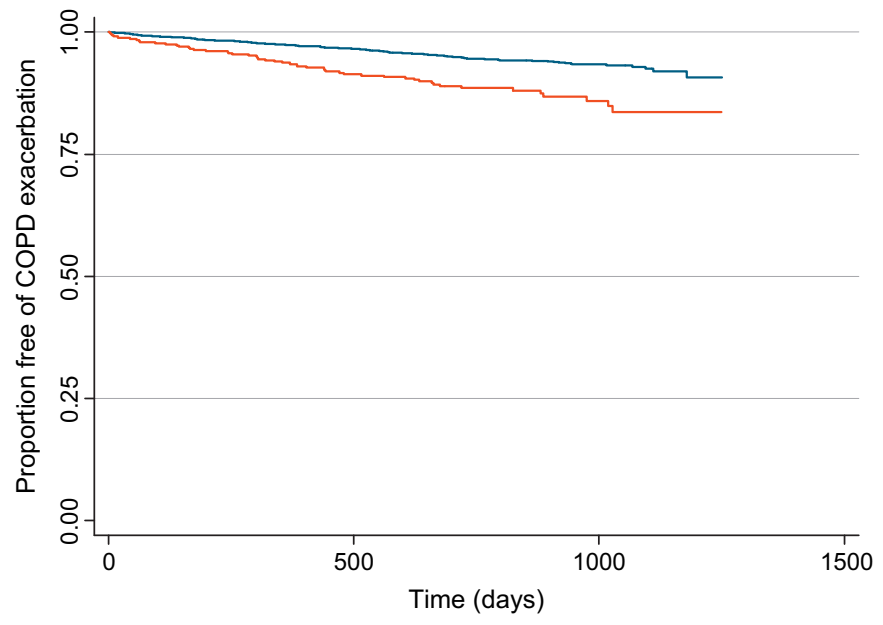

Figure 2 Anxiety and the risk of an exacerbation of chronic obstructive pulmonary disease (COPD) requiring emergency healthcare utilisation. The red line represents subjects with anxiety And the blue line represents subjects without anxiety. $p=0.017$ (log-rank test) for difference between the two groups. 
Table 5 Anxiety and longitudinal risk of an exacerbation of chronic obstructive pulmonary disease (COPD)

\begin{tabular}{lcc}
\hline \multirow{2}{*}{$\begin{array}{l}\text { mutcome } \\
\text { measure }\end{array}$} & \multicolumn{1}{l}{ HR for anxious vs non-anxious } & (95\% CI) \\
\cline { 2 - 3 } & Unadjusted & \multicolumn{1}{c}{ Multivariable adjusted } \\
\hline No anxiety & 1.0 (referent) & 1.0 (referent) \\
Anxiety & $1.45(1.07$ to 1.96$)$ & 1.39 (1.007 to 1.90) \\
& $\mathrm{p}=0.018$ & $\mathrm{p}=0.045$ \\
\hline
\end{tabular}

COPD exacerbation was defined as hospital-based care (either emergency department visit or hospitalisation) for COPD during prospective follow-up. Cox proportional hazards analysis was used.

Multivariable analysis adjusted for age, sex, race, educational attainment, household income and smoking history.

anxiety. Dyspnoea in particular had the strongest association with the risk of anxiety. Anxiety, in turn, had a negative impact on the patient-centred outcomes of physical health status, disease-specific HROL, submaximal exercise performance and functional limitations. It also increased the prospective risk of COPD exacerbations requiring hospital-based care. The relation between anxiety and COPD-related health outcomes was mediated by COPD severity for some outcomes (submaximal exercise performance and COPD exacerbation) and partially mediated for others (physical health status, disease-specific HROL and self-reported functional limitations). Thus COPD appears to increase the likelihood of anxiety, especially as the disease becomes more severe; once established, anxiety exerts a negative impact on health outcomes.

Several studies have found a high prevalence of anxiety among persons with COPD. ${ }^{4}{ }^{44}$ These estimates have been limited by small sample size, inclusion of patients with advanced or end-stage disease and the lack of a control group. This study advances the field by establishing that COPD is associated with a higher risk of anxiety compared with a matched control group in a large number of patients with a broad range of disease severity.

Although COPD severity increased the risk of anxiety, there was no clear impact of physiological impairment of lung function. This observation extends those from a small study of 122 patients with COPD in which the BODE index, and not the

Table 6 Anxiety and COPD-related health outcomes: potential mediation by disease severity

\begin{tabular}{lll}
\hline & $\begin{array}{l}\text { Change in each outcome for anxious vs non- } \\
\text { anxious* }\end{array}$ & $\begin{array}{l}\text { Multivariable } \\
\text { adjusted }+\end{array}$ \\
\cline { 2 - 3 } COPD severity & $\begin{array}{l}\text { Multivariable } \\
\text { adjusted* }\end{array}$ \\
\hline Outcome measure & -4.66 & -2.61 \\
\hline $\begin{array}{l}\text { Physical health status } \\
\text { (points) }\end{array}$ & $(-6.44$ to -2.89$)$ & $(-4.12$ to -1.10$)$ \\
Disease-specific HROL & $\mathrm{p}<0.0001$ & $\mathrm{p}=0.0007$ \\
(points) & 3.31 & 2.39 \\
& $(2.62$ to 4.00$)$ & $(1.83$ to 2.94$)$ \\
Distance walked in & $\mathrm{p}<0.0001$ & $\mathrm{p}<0.00001$ \\
6 min (feet) & -66.3 & 8.1 \\
& $(-127.3$ to -5.36$)$ & $(-38.4$ to 54.6$)$ \\
Risk of self-reported & $\mathrm{p}=0.033$ & $\mathrm{p}=0.73$ \\
physical functional & OR 2.41 & $0 R$ \\
limitations & $(1.71$ to 3.41$)$ & $(1.34$ to 2.95$)$ \\
Longitudinal risk of & $\mathrm{p}<0.0001$ & $\mathrm{p}=0.0007$ \\
COPD exacerbation & HR 1.39 & $\mathrm{HR} 1.052$ \\
& $(1.007$ to 1.90$)$ & $(0.76$ to 1.45$)$ \\
& $\mathrm{p}=0.045$ & $\mathrm{p}=0.76$ \\
\hline
\end{tabular}

Multivariable analysis adjusted for age, sex, race, educational attainment, household income and smoking history.

*This column summarises multivariable results from tables 4 and 5 for comparison with severity-adjusted results.

†Models also include both COPD severity score and BODE index as measures of COPD severity.

$\mathrm{COPD}$, chronic obstructive pulmonary disease; HROL, health-related quality of life.
GOLD stage based on lung function, was related to anxiety. ${ }^{18} \mathrm{~A}$ larger Nordic study also found no relationship between GOLD stage and anxiety among patients with severe COPD. ${ }^{45}$ Our findings reinforce the concept that a comprehensive measure of disease severity, and not just physiological impairment, is required to study the impact of psychosocial factors in COPD.

Our analysis clarifies the impact of anxiety on COPD exacerbation. Although depression has been established as a risk factor for COPD exacerbation, the role of anxiety has been less clear. $^{6} 104647$ In the FLOW cohort study, which has more statistical power than previous investigations, anxiety was a prospective risk factor for COPD exacerbation requiring emergency healthcare utilisation. This effect was, however, entirely explained by the impact of anxiety on greater COPD severity.

Anxiety has a broad negative impact on patient-centred health outcomes in COPD. We theorise that the cognitive aspects of anxiety (which include concentration difficulty and fearful thoughts) will have a major impact on HROL and exacerbations whereas the symptoms of physiological arousal such as sweating and muscle tension may greatly affect physical health status, exercise performance and functional limitations. We expect the emotional and behavioural correlates of anxiety to have a more global impact on health outcomes. Future work is needed to parse out these specific effects of anxiety on health outcomes.

\section{Implications for treatment of COPD}

The mediation analysis has implications for treatment. For some health outcomes (submaximal exercise capacity and COPD exacerbation), the impact of anxiety appeared to be mediated entirely by COPD severity. In our theoretical framework, higher levels of anxiety lead to increased COPD severity which, in turn, adversely affects health outcomes. Consequently, comprehensive treatment of COPD with the aim of decreasing its severity should be the initial goal to improve exercise performance and reduce exacerbations. If response to treatment is partial or inadequate, then treatment of anxiety may be indicated. For physical health status, disease-specific HROL and functional limitations, treatment of anxiety may improve outcomes even after maximising treatments aimed at reducing COPD severity.

\section{Study limitations}

Our study has several limitations. Although we used a reliable and valid measure of anxiety, it is not a clinical diagnosis of generalised anxiety disorder or any other specific DSM-IV diagnosis. We were also not able to evaluate change in anxiety over time. In addition, there is some possibility of misclassification of COPD, although we took rigorous steps to avoid this. The inclusion criteria required a physician diagnosis of COPD, healthcare utilisation for COPD and dispensing of COPD medications, which was designed to increase the accuracy of case ascertainment. We have previously demonstrated the validity of our approach using medical record review. ${ }^{13}$ Nonetheless, we acknowledge this potential limitation.

In addition, we acknowledge that the causal pathway between anxiety and COPD is complex. We theorised that the most important pathway is that worse COPD symptoms and disease severity increase the risk of anxiety which then leads to poorer health outcomes; anxiety also feeds back to increase disease severity and affect health outcomes. Alternatively, it is possible that the primary mechanism could be anxiety increasing disease severity and, consequently, poorer health outcomes. COPD exacerbations may also mimic anxiety which further increases the complexity. Our results must be interpreted in light of the theoretical framework upon which they are based. 


\section{CONCLUSIONS}

COPD is associated with a higher risk of anxiety; once anxiety develops, it is related to poorer health outcomes, some of which are mediated by disease severity. Further research is needed to determine whether systematic screening and treatment of anxiety in COPD will improve health outcomes and prevent functional decline and disability.

Funding National Heart, Lung, and Blood Institute/National Institutes of Health R01HL077618 and K24 HL 097245. Other funders: NIH.

Competing interests None.

Ethics approval The study was approved by the University of California, San Francisco Committee on Human Research and the Kaiser Foundation Research Institute's institutional review board and all participants provided written informed consent.

Provenance and peer review Not commissioned; externally peer reviewed.

\section{REFERENCES}

1. Tashkin DP, Celli B, Senn S, et al. A 4-year trial of tiotropium in chronic obstructive pulmonary disease. N Engl J Med 2008;359:1543-54.

2. Wedzicha JA, Calverley PM, Seemungal TA, et al. The prevention of chronic obstructive pulmonary disease exacerbations by salmeterol/fluticasone propionate or tiotropium bromide. Am J Respir Crit Care Med 2008:177:19-26.

3. Singh D, Brooks J, Hagan G, et al. Superiority of "triple" therapy with salmeterol/ fluticasone propionate and tiotropium bromide versus individual components in moderate to severe COPD. Thorax 2008;63:592-8.

4. Celli BR, Thomas NE, Anderson JA, et al. Effect of pharmacotherapy on rate of decline of lung function in chronic obstructive pulmonary disease: results from the TORCH study. Am J Respir Crit Care Med 2008;178:332-8.

5. Eisner MD, Blanc PD, Yelin EH, et al. COPD as a systemic disease: impact on physical functional limitations. Am J Med 2008;121:789-96.

6. Omachi TA, Katz PP, Yelin EH, et al. Depression and health-related quality of life in chronic obstructive pulmonary disease. Am J Med 2009:122:778.e9-15.

7. Hill K, Geist R, Goldstein RS, et al. Anxiety and depression in end-stage COPD. Eur Respir J 2008:31:667-77.

8. Goodwin RD, Zvolensky MJ, Keyes KM. Nicotine dependence and mental disorders among adults in the USA: evaluating the role of the mode of administration. Psychol Med 2008:38:1277-86.

9. Maurer J, Rebbapragada V, Borson S, et al. Anxiety and depression in COPD: current understanding, unanswered questions, and research needs. Chest 2008; 134(4 Suppl):43S-56S

10. Xu W, Collet JP, Shapiro S, et al. Independent effect of depression and anxiety on chronic obstructive pulmonary disease exacerbations and hospitalizations. Am J Respir Crit Care Med 2008:178:913-20.

11. Eisner MD, lribarren C, Yelin EH, et al. Pulmonary function and the risk of functional limitation in chronic obstructive pulmonary disease. Am J Epidemiol 2008:167:1090-101.

12. Blanc PD, Iribarren C, Trupin L, et al. Occupational exposures and the risk of COPD: dusty trades revisited. Thorax 2009;64:6-12.

13. Sidney S, Sorel M, Quesenberry CP Jr, et al. COPD and incident cardiovascular disease hospitalizations and mortality: Kaiser Permanente Medical Care Program. Chest 2005:128:2068-75

14. American Psychiatric Association. Diagnostic and statistical manual of mental disorders DSM IV. Arlington, VA: American Psychiatric Publishing, 1994

15. Zigmond AS, Snaith RP. The hospital anxiety and depression scale. Acta Psychiatr Scand 1983; 67:361-70.

16. Mykletun A, Stordal E, Dahl AA. Hospital Anxiety and Depression (HAD) scale: factor structure, item analyses and internal consistency in a large population. Br J Psychiatry 2001;179:540-4.

17. Bjelland I, Dahl AA, Haug TT, et al. The validity of the Hospital Anxiety and Depression Scale. An updated literature review. J Psychosom Res 2002;52:69-77.

18. Funk GC, Kirchheiner K, Burghuber OC, et al. BODE index versus GOLD classification for explaining anxious and depressive symptoms in patients with COPD: a crosssectional study. Respir Res 2009;10:1.
19. Puhan MA, Frey M, Buchi S, et al. The minimal important difference of the hospita anxiety and depression scale in patients with chronic obstructive pulmonary disease. Health Qual Life Outcomes 2008;6:46.

20. Eisner MD, Trupin L, Katz PP, et al. Development and validation of a survey-based COPD severity score. Chest 2005;127:1890-7.

21. Celli BR, Cote CG, Marin JM, et al. The body-mass index, airflow obstruction, dyspnea, and exercise capacity index in chronic obstructive pulmonary disease. N Engl J Med 2004;350:1005-12.

22. Hajiro T, Nishimura K, Tsukino M, et al. Analysis of clinical methods used to evaluate dyspnea in patients with chronic obstructive pulmonary disease. Am J Respir Crit Care Med 1998;158:1185-9.

23. Martinez FJ, Han MK, Andrei AC, et al. Longitudinal change in the BODE index predicts mortality in severe emphysema. Am J Respir Crit Care Med 2008;178:491-9.

24. Ong KC, Lu SJ, Soh CS. Does the multidimensional grading system (BODE) correspond to differences in health status of patients with COPD? Int J Chron Obstruct Pulmon Dis 2006;1:91-6.

25. Eisner MD, Iribarren C, Yelin E. The BODE index and COPD severity score offer complementary assessment of COPD status. Am J Respir Crit Care Med 2008;177 A399.

26. American Thoracic Society. Standardization of spirometry-1987 update. Statement of the American Thoracic Society. Am Rev Respir Dis 1987;136:1285-98.

27. American Thoracic Society. Standardization of spirometry, 1994 update. Am J Respir Crit Care Med 1995:152:1107-36.

28. Walters JA, Wood-Baker R, Walls J, et al. Stability of the EasyOne ultrasonic spirometer for use in general practice. Respirology 2006;11:306-10.

29. Perez-Padilla R, Vazquez-Garcia JC, Marquez MN, et al. The long-term stability of portable spirometers used in a multinational study of the prevalence of chronic obstructive pulmonary disease. Respir Care 2006:51:1167-71.

30. Buist AS, McBurnie MA, Vollmer WM, et al. International variation in the prevalence of COPD (the BOLD Study): a population-based prevalence study. Lancet 2007;370:741-50.

31. Ware J Jr, Kosinski M, Keller SD. A 12-item short-form health survey: construction of scales and preliminary tests of reliability and validity. Med Care 1996;34:220-33.

32. Hajiro T, Nishimura K, Jones PW, et al. A novel, short, and simple questionnaire to measure health-related quality of life in patients with chronic obstructive pulmonary disease. Am J Respir Crit Care Med 1999;159:1874-8.

33. Chen H, Eisner MD, Katz PP, et al. Measuring disease-specific quality of life in obstructive airway disease: validation of a modified version of the airways questionnaire 20. Chest 2006;129:1644-52

34. Alemayehu B, Aubert RE, Feifer RA, et al. Comparative analysis of two quality-of-life instruments for patients with chronic obstructive pulmonary disease. Value Health 2002;5:436-41.

35. Guyatt GH, Sullivan MJ, Thompson PJ, et al. The 6-minute walk: a new measure of exercise capacity in patients with chronic heart failure. Can Med Assoc $\mathrm{J}$ 1985:132:919-23.

36. Sciurba F, Criner GJ, Lee SM, et al. Six-minute walk distance in chronic obstructive pulmonary disease: reproducibility and effect of walking course layout and length. $\mathrm{Am}$ J Respir Crit Care Med 2003;167:1522-7.

37. American Thoracic Society. ATS statement: guidelines for the six-minute walk test. Am J Respir Crit Care Med 2002;166:111-7.

38. Sternfeld B, Ngo L, Satariano WA, et al. Associations of body composition with physical performance and self-reported functional limitation in elderly men and women. Am J Epidemiol 2002;156:110-21.

39. Centers for Disease Control and Prevention (CDC). Cigarette smoking among adults - United States, 1997. MMWR Morb Mortal Wkly Rep 1999;48:993-6.

40. Anon. National Center for Health Statistics. National Health Interview Survey.

41. Norman GR, Sloan JA, Wyrwich KW. Interpretation of changes in health-related quality of life: the remarkable universality of half a standard deviation. Med Care 2003;41:582-92.

42. Schoenfeld $\mathbf{D}$. Partial residuals for the proportional hazards regression model. Biometrika 1982;69:239-41.

43. Rothman KJ, Greenland S. Modern epidemiology. Philadelphia: Lippincott-Raven Publishers, 1998.

44. Putman-Casdorph H, McCrone S. Chronic obstructive pulmonary disease, anxiety, and depression: state of the science. Heart Lung 2009;38:34-47.

45. Gudmundsson G, Gislason T, Janson C, et al. Depression, anxiety and health status after hospitalisation for COPD: a multicentre study in the Nordic countries. Respir Med 2006;100:87-93

46. Gudmundsson G, Gislason T, Janson C, et al. Risk factors for rehospitalisation in COPD: role of health status, anxiety and depression. Eur Respir J 2005;26:414-9.

47. Kim HF, Kunik ME, Molinari VA, et al. Functional impairment in COPD patients: the impact of anxiety and depression. Psychosomatics 2000;41:465-71. 